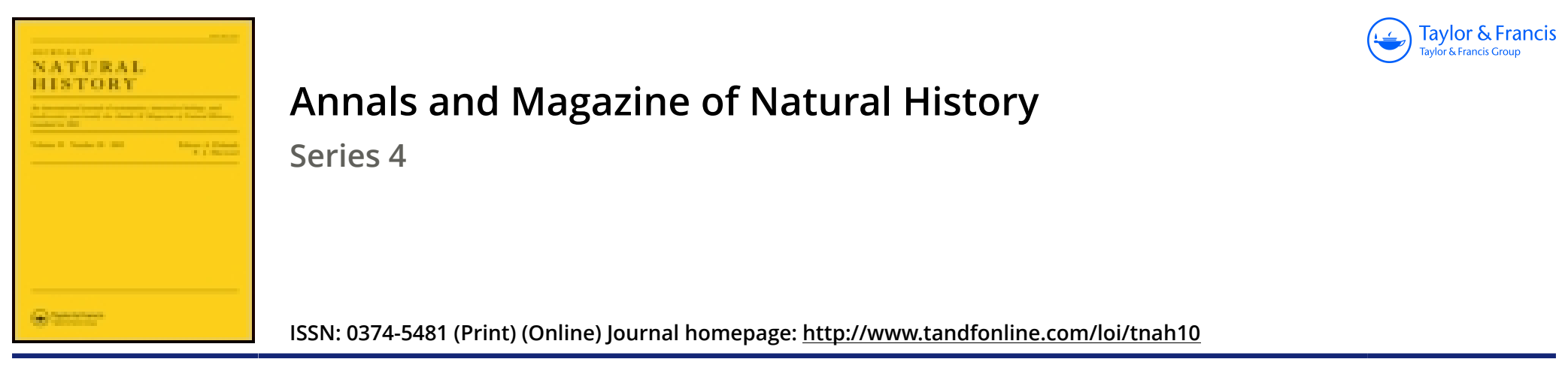

\title{
On the first phenomena of the development of Echinus miliaris
}

\section{M.A. Giard}

To cite this article: M.A. Giard (1877) On the first phenomena of the development of Echinus miliaris, Annals and Magazine of Natural History, 19:113, 434-436, DOI: 10.1080/00222937708682173

To link to this article: http://dx.doi.org/10.1080/00222937708682173

$$
\text { 册 Published online: } 13 \text { Oct } 2009 .
$$

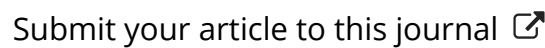

Џ Article views: 1 
post if convenient, after the receipt of the Boxes, with these words alone, or instead of them any other observation you consider necessary.

"As stated to you before, I can vouch for the accuracy of what I have published respecting the Type or New Specimens among these Sponges; and that is all that Science requires or can demand, either from my head or my pocket, gratuitously.

"I am, my dear Thomson,

$$
\begin{aligned}
& \text { "To (Signed) Hours very truly, } \\
& \text { Professor Sir Wyville Thomson, } \\
& 20 \text { Palmerston Place, } \\
& \text { Edinburgh." }
\end{aligned}
$$

Of the Boxes having reached their destination I had notice by tho receipt of the "Postal Card" on the 28th March, signed "C. Wy. T.," and stating that they had "arrived all right," but had "not" been "opened." So far I am no longer accountable for these specimens.

Budleigh-Salterton, April 25, 1877.

\section{On the first Phenomena of the Development of Echinus miliaris.} By M. A. Giard.

The important controversies to which the investigation of the first development of the egg of the Echinodermata have given rise have led me this winter to undertake a series of researches upon the common urchin of the shores of the Boulonnais, Psammechinus miliaris. As a term of comparison in some diffeult points I had the eggs of the common starfish (Asteracanthion rubens). The spawning ceases in both species towards the end of March.

The methods employed by me are those of direct observation and of coloured preparations. The latter were especially useful for the observation of the caryolytic figures (Auerbach) or amphiasters (H. Fol). I obtained excellent results by employing acetic acid, ammoniacal carmine, and picric acid, applying these reagents successively and in very small quantitics. The preparations thus obtained are very beautiful; but, unfortunately, they cannot be preserved more than a few days.

Besides the mucous envelope the egg of Echinus mitiaris possesses a very delicate vitelline membrane, and this even before fecundation, as has been asserted with regard to allied species by 0 . Hertwig and Perez. A little while before maturity the germinal vesicle presents the reticulum characteristic of old nuclei. The nuclcolus contains an irregular nucleolinus. When the egg is mature, the gorminal vesicle quits the central point and enters upon re rogression. Its elements, mingled with those of the nucloolus, form an amoboid mass with more or less torn outlines, which soon attains the periphery of the vitellus, when it divides into two parts, producing a caryolytic figure. One of the stars is directed towards the centre of the egg, and very rapidly acquires the form of a rounded nucleus. It is this nucleus that 0 . Hertwig regards as the germinal spot, which has escaped the transformation affecting the germinal 
resicle. We shall, like $H$. Fol, call it the female pronucleus. This nucleus always appeared to me smaller than the nucleolus of the egg-an observation which appears to me difficult to reconcile with the opinion of $O$. Hertwig. Moreover I have frequently met with ova in which the Wagnerian spot was no longer visible, and in which the female pronucleus did not yet clearly preaent the nuclear appearance. On the other hand, it is incorrect to say that the female pronacleus has no genetic connexion with the nucleolus of the ovule, seeing that the substance of that nucleolus, mixed with that of the germinal vesicle, serves for the formation of the first amphicaster, which gives birth to the female pronucleus.

By examining, without reagents, a great number of eggs recently deposited and not yet fecundated, we observe very interesting facts. The egg presents two little cumuli of a protoplasm clearer than the rest of the vitelline mass. These two cumuli may be varionsly placed with respect to each other; but very generally they are placed at the extremities of one diameter. One of them originates at the expense of the brother star of the female pronucleus; this star forms an unequal caryolytic figure, the small star of which becomes the cumulus in question; this cumulus, lastly, produces the first polar globule; the second originates subsequently from the first. The polar globules are very small in the urchin, and, moreover, they disappear rery rapidly; lastly, they do not remove far from the surface of the vitellus, and it is therefore possible that in Toxopneustes lividus they may have escaped the notice even of so practised an observer as 0 . Hertwig.

I have said that in order to make these observations it is necessary to take recently deposited eggs: the deposition may be indnced at will in several ways. The same phenomena may also be observed, however, in ova taken directly from the genital gland; but in operating thus we are exposed to a source of error. In fact, with the liquid of the perivisceral cavity a certain number of the amoboid elements which float in that liquid are very frequently removed; and these elements, by attaching themselves to the surface of the vitelline membrane, which is intimately applied to the vitellus, may simulate vitelline cumuli or even polar globules. All confusion is aroided by taking deposited eggs, and following them step by step for some time up to the moment of fecundation.

As soon as the egg is brought into contact with the spermatozoids, the latter apply thenselves by their heads over the whole periphery of the membrane, and impress upon the vitelline sphere a very rapid gyratory morement. The vitelline membrane, hitherto very close to the surface of the vitellus, separates from it by degrees; and, in consequence, the second cumulus, the apex of which adheres to the membrane, is drawn out into a cone, uniting the ritellus to the surface. As no spermatozoid is seen to penetrate between the vitelline membrane and the vitellus, round which there exists a large clear space, I ineline to think that the second cumulus serves for the passage of the spermatozoid, either by the apex of the cone terminating at a pore in the membrane, or (which appears to me more jrobable) by the fecundating act consisting essentially in a diffusion 
of the male protoplasn through the membrane at the point where this is directly in contact with the female protoplasm - that is to say, at the apex of the cumulus.

The protoplasmic cone uniting the membrane with the vitellus soon detaches itself from the membrane and reenters into the vite line mass. By employing colouring substances the egg then presents three nuclei, two situated near one pole of the egg, the other at the opposite pole. Of the former two, the superficial one is the nucleus which, by dividing, forms the polar globules; the other, more deeply seated, is the female pronucleus; the nucleus formed at the opposite pole, which is at first superficial, is the male pronucleus, which, starting from the point where the cumulus of fecundation was situated, directs itself towards the centre of the egg to meet with the female pronucleus, with which it enters into conjugation to form the first nucleus of segmentation. I do not think that the nucleolus of the male pronucleus can be regarded as the unmodified head of a spermatozoid.

It seems to me that the numerous spermatozoids fixed upon the membrane of the egg, and which appear to have no function, are not quite without influence on the act of fecundation. The gyratory movement which they give to the egg, a movement so easily detected in the Echinodermata, the Ascidia, and a great many other animals, perhaps assists in favouring the progress of the two pronucle $i$ towards the centre of the egg. I have frequently remarked that the eggs which had not turned for a certain time were developed irregularly, and sometimes even did not enter into embryonic evolution.

Is the existence of a cumulus of fecundation peculiar to the Echinodermata? Prof. de Lacaze-Duthiers, in his splendid monograph of Dentalium, figures in the egg of that mollusk a mumilla situated at the pole opposite to the polar globules, and which may perhaps have the same signification as the cumulus of the urchin. However the eminent zoologist declares that he could not say whether this mamilla is visible before the arrival of the spermatozoids.

In the common starfish the cumulus of fecundation is more difficult to see than in the urchin; but, on the other hand, the polar globules are much more apparent, and their production presents more clearly the picture of a cell-division with unequal products.Comptes Rendus, April 9, 1877, p. 720.

\section{Obituary.}

JонN Lecken вy, Esq., F.G.S., F.L.S., died at Searborough on the 7 th of April, 1877, in the 63rd year of his age. He was an excellent and zealous naturalist, and deservedly possessed the esteem of all his numerous friends and correspondents. Yorkshire has lost in him one of her best men of science. Mr. Leckenby became a contributor to the 'Annals' in 1858; and his last communication was made, in conjunction with Mr. Marshall, in December 1875. He also published papers on local geology in the 'Quarterly Journal of the Geological Society' and the 'Geologist' in 1859. 